\title{
Qualidade sanitária de embutidos coletados no mercado público central de Porto Alegre-RS
}

\author{
Microbial safety of sausage collected in the central market of \\ Porto Alegre-RS, Brazil
}

\author{
Rosângela Uhrig Salvatori ${ }^{1}$ Marjo Cadó Bessa ${ }^{2}$ \\ Marisa Ribeiro de Itapema Cardoso ${ }^{3}$
}

RESUMO

Noventa e três amostras de embutidos coletados no Mercado Público Central de Porto Alegre foram analisadas quanto à presença de Salmonella sp. e à contagem de coliformes fecais. Todos as amostras apresentaram ausência de Salmonella sp., enquanto, em relação aos coliformes fecais, constatou-se que quatorze amostras de embutidos frescais encontravam-se acima do padrão estabelecido pela portaria $n^{\circ} 451$, em vigor no momento da coleta. Entretanto, se fossem considerados os parâmetros estabelecidos na Resolução $n^{\circ}$ 12, em vigor atualmente, apenas cinco amostras seriam consideradas fora de padrão. A maioria das amostras com contagens de coliformes fecais acima de $5 \times 10^{2} / \mathrm{g}$ estava armazenadas acima da temperatura adequada no momento da coleta.

Palavras-chave: Salmonella, embutidos, coliformes fecais.

\section{ABSTRACT}

Ninety-three sausage samples collected in the Central Market of Porto Alegre-RS, Brazil were analyzed for the occurrence of Salmonella sp. and fecal coliform counts. Salmonella sp. was absent in all collected samples. Fourteen samples of fresh pork sausage had fecal coliform counts above the established in the legislation in force at the time of sample collection. On the other hand, only five of these samples would be classified as unfit to be consumed, according the legislation in force now. Most samples with fecal counts above $5 \times 10^{2} / \mathrm{g}$ were from sausages stored at temperatures above the recommended at the time of collection.

Key words: Salmonella, sausage, fecal coliforms.

Coliformes fecais têm sido usados para determinar condições sanitárias insatisfatórias de alimentos e presença potencial de patógenos (JAY, 1992). A presença de Salmonella spp. em alimentos, por sua vez, torna o mesmo impróprio para o consumo, uma vez que esse é reconhecidamente um microrganismo implicado em surtos de toxinfecção alimentar. O limite permitido desses microrganismos, para os diferentes alimentos, é estabelecido por legislação em cada país. No Brasil, a partir de janeiro de 2001, passou a vigorar nova resolução que modificou os padrões microbiológicos previstos anteriormente, como forma de compatibilizar a legislação nacional com regulamentos harmonizados no Mercosul (ANVISA, 2001). Por outro lado, há uma preocupação crescente quanto à importância de produtos cárneos derivados de suínos como possíveis veiculadores de Salmonella sp. para o consumidor, principalmente produtos que não sofram uma etapa de eliminação de microrganismos durante seu processamento (BLAHA, 1996). No Sul

${ }^{1}$ Biólogo, Mestre, Professora da Fundação Alto Taquari de Ensino Superior (Fates).

${ }^{2}$ Farmacêutico, Mestre em Microbiologia Agrícola e do Ambiente, Universidade Federal do Rio Grande do Sul (UFRGS).

${ }^{3}$ Médico Veterinário, Professor Titular, Departamento de Medicina Veterinária Preventiva, Faculdade de Veterinária, UFRGS, Av.

Bento Gonçalves 9090, 91540-000, Porto Alegre-RS. mcardoso@vortex.ufrgs.brAutor para correspondência. 
do Brasil, poucas são as investigações da qualidade microbiológica de produtos cárneos disponíveis no comércio. Desta forma, o presente trabalho objetivou determinar a ocorrência de Salmonella sp. e verificar o nível de coliformes fecais em amostras de embutidos, preparados com carne suína, coletadas em estabelecimentos comerciais do Mercado Público de Porto Alegre. Um total de 93 amostras de embutidos, cujo ingrediente principal era a carne suína, foram coletadas, aleatoriamente, em diferentes bancas do Mercado Público de Porto Alegre, no ano de 1998. O local foi escolhido por apresentar variabilidade de estabelecimentos e produtos disponíveis, bem como por atender parcela considerável de consumidores da cidade. Nos estabelecimentos visitados, foram adquiridos, no mínimo, 200g de cada um dos produtos, de acordo com a disponibilidade no momento da coleta. Do total de amostras coletadas, 70 eram embutidos frescais (lingüiças cruas e similares) e 23 produtos cárneos maturados (salames e lingüiças dessecadas). As amostras foram mantidas nas condições de temperatura em que se encontravam no comércio e processadas no mesmo dia da coleta. De cada produto, foram retirados $25 \mathrm{~g}$ assepticamente, procedendo-se à homogeneização em $225 \mathrm{~mL}$ de água peptonada tamponada, a partir da qual realizaram-se diluições seriadas até $10^{-3}$. A contagem de coliformes totais foi realizada em ágar Vermelho Violeta Bile (VRB, Merck), conforme SILVA et al. (1997). A confirmação de coliformes fecais foi feita em caldo EC (Difco), semeando-se o número de colônias equivalente à raiz quadrada da média aritmética das contagens obtidas nas placas de VRB (CARDOSO et al., 1985). Os tubos inoculados foram incubados $\left(48 \mathrm{~h} / 44,5^{\circ} \mathrm{C}\right)$ em banho-maria sob agitação (68rpm/min). Dos tubos positivos, foi transferida uma alíquota para ágar Eosina Azul de Metileno (EMB, Difco) para confirmação da presenças de Escherichia coli. Para pesquisa de Salmonella sp., o material foi submetido ao pré-enriquecimento em água peptonada tamponada $\left(24 \mathrm{~h} / 35^{\circ} \mathrm{C}\right)$ seguido de enriquecimento seletivo em caldo RappaportVassiliadis (Merck) $\left(24 \mathrm{~h} / 42^{\circ} \mathrm{C}\right)$ e isolamento em ágar XLT4 (Difco) e ágar Rambach (Merck). Colônias suspeitas de Salmonella sp. foram identificadas conforme SILVA et al. (1997).Observou-se ausência de Salmonella sp. nas 93 amostras processadas, conforme exigido pela legislação vigente. Por outro lado, as contagens de coliformes fecais, em embutidos frescais e maturados, apresentaram níveis variados. Todos os embutidos maturados $(n=23)$ apresentaram contagens de coliformes fecais até 30 unidades formadoras de colônia/g (ufc/g), estando dentro do padrão exigido. A maioria dos embutidos deste grupo $(n=19)$ tinha contagens de coliformes fecais abaixo de 11 ufc/g. Já entre os embutidos frescais, 56 amostras apresentavam até $500 \mathrm{ufc} / \mathrm{g}$ de coliformes fecais, enquanto as 14 amostras restantes apresentavam contagens superiores. Considerando que as coletas foram realizadas antes da mudança de legislação e que a portaria vigente na época (Brasil, 1997) estabelecia limite máximo de coliformes fecais de $5 \times 10^{2} / \mathrm{g}$, essas 14 amostras estavam fora dos padrões sanitários (Tabela 1). Entretanto, analisando as mesmas amostras, conforme a legislação em vigor atualmente, apenas 5 amostras seriam classificadas como em condições sanitárias insatisfatórias (coliformes fecais acima de $5 \times 10^{3} / \mathrm{g}$ ). Essas cinco amostras haviam sido coletadas no verão e encontravam-se expostas no balcão, não sujeitas à refrigeração. Ainda, outras 7 amostras, que estariam fora apenas do padrão fixado pela portaria 451, também encontravam-se fora da refrigeração no momento da coleta. A qualidade dos embutidos frescais está diretamente relacionada à qualidade da matéria-prima e das boas práticas de manufatura e armazenamento, uma vez que não sofrem tratamento térmico durante seu processamento (JAY, 1992). Esta preocupação deve estar presente em todas as etapas, inclusive no momento da comercialização. É possível constatar que, apesar de a maioria dos produtos coletados apresentar

Tabela 1 - Contagens de coliformes totais, fecais e Escherichia coli encontrados em embutidos coletados no Mercado Público de Porto Alegre, em 1998.

\begin{tabular}{lccc}
\hline Amostra & $\begin{array}{c}\text { Coliformes totais } \\
\text { Ufc/g }\end{array}$ & $\begin{array}{c}\text { Coliformes fecais } \\
\text { Ufc/g }\end{array}$ & $\begin{array}{c}\text { Escherichia coli } \\
\text { Ufc/g }\end{array}$ \\
\hline 1 & $2,5 \times 10^{5}$ & $1,9 \times 10^{5 a, b}$ & $3,1 \times 10^{4}$ \\
2 & $1,6 \times 10^{5}$ & $1,2 \times 10^{5 a, b}$ & $6,1 \times 10^{4}$ \\
3 & $3,1 \times 10^{4}$ & $1,0 \times 10^{4 a, b}$ & $5,0 \times 10^{3}$ \\
4 & $6,7 \times 10^{3}$ & $6,7 \times 10^{3 a, b}$ & $1,6 \times 10^{3}$ \\
5 & $6,8 \times 10^{3}$ & $5,9 \times 10^{3 a, b}$ & $3,4 \times 10^{3}$ \\
6 & $6,4 \times 10^{3}$ & $4,8 \times 10^{3 a}$ & $3,2 \times 10^{3}$ \\
7 & $4,6 \times 10^{3}$ & $4,6 \times 10^{3 a}$ & $6,0 \times 10^{2}$ \\
8 & $3,6 \times 10^{3}$ & $1,8 \times 10^{3 a}$ & $1,8 \times 10^{3}$ \\
9 & $3,2 \times 10^{3}$ & $1,5 \times 10^{3 a}$ & $<1,0 \times 10^{1}$ \\
10 & $3,0 \times 10^{3}$ & $1,0 \times 10^{3 a}$ & $<1,0 \times 10^{1}$ \\
11 & $1,5 \times 10^{3}$ & $8,7 \times 10^{2 a}$ & $6,2 \times 10^{2}$ \\
12 & $6,3 \times 10^{3}$ & $7,8 \times 10^{2 a}$ & $7,8 \times 10^{2}$ \\
13 & $1,5 \times 10^{3}$ & $5,7 \times 10^{2 a}$ & $3,4 \times 10^{2}$ \\
14 & $2,7 \times 10^{3}$ & $5,4 \times 10^{2 a}$ & $5,4 \times 10^{2}$ \\
\hline
\end{tabular}

$a$ - Amostras fora dos padrões da Portaria 451, 1997.

$b$ - Amostras fora dos padrões da Resolução $\mathrm{n}^{\circ} 12,2001$. 
condições sanitárias adequadas, as boas práticas de armazenamento continuam a não ser seguidas por alguns estabelecimentos, podendo ter sido a causa das contagens de coliformes fecais encontradas fora de padrão. A modificação dos padrões previstos pela legislação, por sua vez, resultou num sensível decréscimo de amostras classificadas como em condição sanitária inadequada. Entretanto, a avaliação do significado desta modificação depende de estudos que determinem o risco que diferentes contagens de coliformes fecais representam para a saúde humana.

\section{REFERÊNCIAS BIBLIOGRÁFICAS}

ANVISA. Resolução -RDC $\mathbf{n}^{\circ} \mathbf{1 2}$, de 02 de janeiro de 2001. A rquivo capturado em 04 de julho de 2001. On line. Disponível na internet via http://www.anvisa.gov.br/legis/resol/

\section{$\underline{12-01 \mathrm{rdc} . \mathrm{html}}$.}

BLAHA, T. The impact of Salmonella on the swine industry. In: The Allen D, Leman swine cConference. St Paul : 1996. p.1-20

BRASIL. Ministério da Saúde. Secretaria de Vigilância Sanitária. Portaria 451 de 19/09/1997. Diário Oficial de 02 de julho de 1998. N.124. Brasília : Imprensa Oficial, DF, 1998. p.413 .

CARDOSO, V.M.; SILVA, G.G.; CANO, V. Contagem de microrganismos. In: Análises microbiológicas de alimentos. Rio de Janeiro : QUIMITRA, 1985. p.20-27.

JAY, J.M. Modern food microbiology. 5.ed. New York : Chapman \& Hall, 1992. 661p.

SILVA, N.; JUNQUEIRA,V.C.A.; SILVEIRA,N.F.A. Manual de métodos de análise microbiológica de alimentos. São Paulo: Varela, 1997. 295p. 